\title{
ESTUDIOS
}

\section{La contribución de las universidades a la dignificación de la vida pública}

\section{Augusto Hortal Alonso, $\mathbf{S} \mathbf{J}^{\prime}$}

Palabras claves: funciones universitarias; bienes internos; formación profesional; ética; mundo plural.

Key words: university duties; internal goods; professional formation; ethics; plural world.

La ética de la vida pública es responsabilidad de todos los que de una u otra forma, con mayor o menor protagonismo, intervienen y se relacionan con la esfera pública: no sólo los políticos y los funcionarios, también los ciudadanos y las diversas instituciones, redes y ámbitos que configuran la sociedad civil contribuyen de una $u$ otra forma a que la vida pública sea vivida con más o menos verdad, transparencia, libertad, justicia, solidaridad, etc. En este contexto no puede faltar una breve reflexión sobre lo que desde las universidades se puede y debe hacer como contribución necesaria o deseable a que esa misma vida pública sea vivida éticamente.

\section{I.Ser verdaderamente universidad}

La contribución más importante que pueden y deben hacer las universidades a la vida pública en general y a que ésta sea vivida con justicia y verdad en libertad es

' Profesor de la Universidad Pontificia Comillas. 
ser auténticas universidades en las que se investigan, se enseñan, se difunden y se aplican los conocimientos crítica y metodológicamente acreditados, poniéndolos a disposición de la sociedad para que todos puedan vivir una vida digna y próspera. De las universidades no cabe esperar más, pero tampoco menos. Difícilmente pueden hacer mejor contribución que aportar aquello mismo que se espera de ellas, para lo que se tienen y se financian las universidades. Eso tiene además un efecto positivo, es ejemplarizante para la vida pública que la universidad y cada institución cumpla con la misión social que tiene encomendada. Pocas cosas son más necesarias para la vida social que el que cada ámbito y cada institución sea lo que tiene que ser, cumpla su cometido. Eso es a la vez el mejor caldo de cultivo de una vida pública que, a la postre, consiste y debe consistir en la buena gestión de todos esos ámbitos al servicio del bien común de todos.

Los universitarios actuales, por lo general, no corren peligro de pretender refugiarse en la "torre de marfil". Si en ocasiones se reivindica el valor del saber por el saber, suele ser más bien para contrarrestar la tendencia a un inmediatismo intelectual excesivamente pragmático que sólo fomenta aplicaciones rentables a corto plazo. Es sabido que la investigación básica es absolutamente necesaria y, aun siendo rentable, no resulta posible ni fecundo someterla a baremos preestablecidos de rentabilidad comprobable a corto plazo. A falta de esos criterios objetivos suelen prevalecer planteamientos más o menos ideologizados o burocratizados, modas intelectuales, intereses corporativos de determinadas camarillas académicas. Más que la tendencia al aislamiento prevalece hoy el peligro de una excesiva aproximación de la vida universitaria a la vida política. Eso hace que se introduzcan mecanismos partidistas, favoritismos políticos que alejan del cultivo de los saberes en sus propios términos y con sus propios criterios.

Si la politización no le hace bien a la vida universitaria, tampoco es bueno reclamar un excesivo protagonismo de los universitarios en la vida pública. Eso conllevaría formas de secuestro corporativo de una esfera pública que, por su propia naturaleza, no debe ser patrimonio exclusivo de unos o de otros grupos, sino de todos.

Por tanto, lo que la vida pública necesita de la universidad y lo que la universidad puede y debe ofrecer a la vida pública es ser verdadera universidad en la que los investigadores investigan y publican lo investigado a ser posible sobre cuestiones relevantes, en la que los profesores enseñan y los estudiantes estudian y aprenden, en la que los conocimientos se difunden a través de actividades de extensión, difusión y asesoramiento. Así es como se puede hacer presente y relevante la aportación intelectual específica de la universidad a las distintas facetas de la vida social, cultural, económica y política. 


\section{Las funciones universitarias y sus bienes internos}

A. Maclntyre ha señalado una diferencia fundamental entre unas actividades que él llama "prácticas" y el resto de las actividades humanas. Lo que según este autor permite distinguir las "prácticas" del resto de las actividades radica en que las prácticas están constitutivamente orientadas a realizar determinados bienes que sólo se pueden conseguir haciendo bien esas "prácticas"; por eso Maclntyre llama a estos bienes internos. Hay en cambio otro tipo de bienes (que él llama externos) que se pueden conseguir realizando diferentes tipos de actividades legítimas o incluso fingiendo que se hacen las "prácticas", pero sin tratar de alcanzar ni realizar los bienes internos a las mismas.

Aumentar los conocimientos en una parcela del saber con arreglo al método científico propio de ese campo es algo que sólo se consigue investigando. En cambio obtener determinado número de puntos por investigación, lograr que te publiquen un artículo que no dice nada especialmente nuevo, pero que engrosa tu currículo, conseguir financiación para tu equipo investigador, etc. se puede conseguir investigando o haciendo como que se investiga, teniendo influencias, amigos, etc. Dinero, poder, prestigio, estatus son bienes externos; se pueden conseguir mediante diferentes actividades, no están intrínsecamente ligados a una sola actividad. Eso no significa que sean reprobables o que necesariamente se obtengan por malas artes, sino sencillamente que no son bienes internos a ninguna actividad específica.

Lo problemático de los bienes externos no está en ellos mismos; es más, son necesarios y van unidos necesariamente a las "prácticas". Para investigar hacen falta medios económicos, financiación; es normal que los buenos investigadores tengan prestigio y obtengan más financiación para continuar investigando. Lo problemático de los bienes externos está en que se invierta la jerarquía entre los bienes internos y los externos. Cuando aquellos se subordinan a éstos, cuando se invierte el orden jerárquico estamos cayendo en la quintaesencia de la corrupción de la "prácticas" en la que la apelación a los bienes externos sólo sirve de tapadera para alcanzar más dinero, más poder, más prestigio, más estatus.

Hace unos años tuve el privilegio y la ocasión de conversar despacio con Alasdair Maclntyre. Estaba relativamente reciente la publicación de su libro Tras la virtud que me había resultado sumamente convincente en su parte crítica y muy sugerente en su propuesta de una ética de las virtudes estrechamente ligada a las "prácticas". Con el afán de aclararme sobre el concepto de "práctica" le pedí que me pusiese algún ejemplo de la vida universitaria. Me respondió que le resultaba muy difícil, porque las universidades eran actualmente un conglomerado de temas, grupos e 
intereses contrapuestos que se resistían a ser descritos en términos de "prácticas". Prevalecía, a su juicio, el hecho de que hoy las universidades son ante todo instituciones al servicio del mantenimiento o mejora de estatus de las clases medias. Es decir, si interpreto bien, el entramado de intereses económicos, de estatus, prestigio y poder en que se desenvuelve la vida universitaria, impide o al menos hace invisible las "prácticas" universitarias. ${ }^{2}$

Tal vez no lleguen a constituir prácticas completamente independientes, pero la investigación, la docencia y la participación en el debate intelectual sobre los diferentes aspectos de la vida pública son bienes internos que sólo se logran investigando, enseñando y debatiendo. Esos bienes constituyen la razón de ser que proporciona legitimidad al quehacer universitario. Incluso quienes utilizan la universidad para otros fines no pueden evitar al menos aparentar que investigan, enseñan y participan en el debate intelectual. No mejora mucho el panorama, más bien empeora, si a los intereses de estatus y prestigio con los que se distorsionan las "prácticas" universitarias, vinieran a añadirse los de la politización y las luchas por el poder. De todos modos, la universidad no puede desentenderse de la vida pública. Es importante que los universitarios tomen parte activa en la vida pública. Son a la vez que universitarios, ciudadanos; son ciudadanos sin dejar de ser universitarios; son universitarios sin dejar de ser ciudadanos. No hay que caer en reivindicar el gobierno de los expertos (tecnocracia), pero toda buena política debería estar bien asesorada, técnica y lúcidamente acompañada por buenos conocedores de lo que se sabe acerca de los temas sobre los que se decide en la vida pública.

\section{La universidad y la formación de profesionales}

Dicho lo anterior, no está dicho todo. La función social de la universidad que de hecho resulta más importante para la vida social y también para la vida pública es la formación profesional, social y humana de los estudiantes actuales y futuros profesionales. La universidad no es, no ha sido nunca, un lugar donde exclusivamente se adquieren determinados conocimientos y métodos y la correspondiente acreditación para ejercer una profesión. Para los estudiantes la etapa universitaria es una etapa decisiva para su inserción social, el último trámite para completar su socialización, algo así como un rito de paso entre la vida joven y

\footnotetext{
2 Posteriormente pude leer un artículo, no especialmente alentador, de MACINTYRE sobre el tema universitario (1999): "La idea de una comunidad ilustrada", Diálogo Filosófico n 21, pp. 324-342.
} 
la vida adulta. Por las aulas universitarias, por los pasillos y cafeterías, y por todo el campus pasan jóvenes que en esos años consolidan sus relaciones, sus capacidades y sus aspiraciones generacionales. Ellos son los que, andando el tiempo, ocuparán puestos de responsabilidad en las empresas, en las instituciones, en los organismos; algunos de ellos también en la vida pública. La etapa universitaria tiene un peso específico en la configuración de la generación que al salir de la universidad se va incorporando a la vida adulta. De cómo sea la vida universitaria y de si lo que en ella sucede logra conectar con sus inquietudes o no, dependerá lo que ellos vayan a ser en el futuro; de lo que ellos sean en el futuro depende en gran medida la valoración que quepa hacer de la contribución de la universidad a la vida pública.

Es importante, para la sociedad, para los mismos estudiantes y para la propia universidad, que lleguen a ser profesionales competentes, pertrechados con los conocimientos, destrezas y capacidades para ejercer responsablemente su profesión. Pero es importante que la ejerzan con sentido y responsabilidad social, con sentido cívico, político, crítico. No sólo formamos profesionales, formamos ciudadanos y, por encima de todo, personas. Esto es especialmente verdadero de nuestros centros universitarios.

\section{La formación en una universidad de la Compañía de Jesús}

La formación de personas es tal vez el rasgo más característico y sobresaliente de una universidad católica en general y de una universidad de la Compañía de Jesús en particular. A los jesuitas nos interesan las personas, creemos en ellas, antes, durante y después de su paso por nuestros colegios y nuestras universidades; tratamos de respetar y promover en todo lo que podemos los procesos de personalización. Algunos de nuestros alumnos podrán llegar a ser buenos investigadores o buenos docentes; lo importante es que lleguen a poner su buen hacer al servicio de los demás, especialmente de los desfavorecidos. La mayoría de nuestros alumnos se preparan para ser profesionales que, ayudados, puedan ellos mismos ayudar a otros a mejorar sus condiciones de vida y a lograr el pleno reconocimiento de su dignidad y sus derechos.

El P. Kolvenbach en su Conferencia de la Universidad de Santa Clara nos lo ha puesto a la vez muy claro y muy difícil: "El criterio real de evaluación de nuestras universidades jesuitas radica en lo que nuestros estudiantes lleguen a ser." "El auténtico criterio para evaluar las universidades de la Compañía no es lo que nuestros 
estudiantes hagan, sino lo que acaben siendo y la responsabilidad cristiana adulta con la cual trabajen en el futuro a favor de sus prójimos y de su mundo." ${ }^{3}$

\section{El lugar de la ética en la formación universitaria}

No hay fórmula mágica para fabricar profesionales éticos, ni ciudadanos solidarios y comprometidos, ni buenas personas. Lo más que se puede hacer desde la universidad, como desde cualquier otro sitio, es proponer y facilitar que quienes quieran serlo, lo puedan ser y lo sean. Para ello nada ayuda más que crecer y formarse en un contexto en el que la ética se viva, se exprese, se practique. La enseñanza de una asignatura de Ética, sin ser decisiva, tiene también su importancia. No hay que creer, como al parecer creía Sócrates, que la maldad procede única y principalmente de la ignorancia. Pero sí cabe decir que actualmente hay dos factores importantes de desmoralización en la vida profesional y social, y todavía más, si cabe, en la vida pública: por una parte está muy extendida la convicción de que sobre ética nada o casi nada se puede decir en términos de racionalidad, y por otra existe una lamentable pero muy arraigada desconexión entre la racionalidad práctica propia de la ética y los enfoques positivistas o pragmatistas de las ciencias y las técnicas. La presencia de una asignatura de Ética en la Universidad -en el aula y fuera de ella-puede y debe contribuir a contrarrestar esas dos convicciones desmoralizantes que, en parte, el mismo funcionamiento universitario tiende a corroborar, como enseguida veremos. Por eso, es importante que lo que se enseñe en la clase de Ética esté a la altura de la vida intelectual y académica propia de una universidad; pero igualmente importante es prestar atención al modo como se relaciona la Ética con el resto de lo que se dice, se enseña y se investiga en la universidad, y también con todo lo que se hace y se vive en la institución universitaria.

La presencia de la Ética profesional en el currículo universitario de una titulación puede favorecer que se tengan en cuenta los fines prácticos por los que se enseña lo que se enseña, se aprende lo que se aprende y se investiga lo que se investiga. Ese horizonte se pierde de vista cuando cada disciplina se encierra en su mundo, en sus planteamientos, métodos y supuestos. Al poner sobre la mesa el tema de lo que cada disciplina contribuye a la mejor comprensión y realiza-

\footnotetext{
${ }^{3}$ P.-H. KOLVENBACH, El servicio de la fe y la promoción de la justicia en la educación universitaria de la Compañía de Jesús de Estados Unidos, Conferencia en la Universidad de Santa Clara (California) octubre de 2000. Este texto ha sido incluido en el libro (2007), Selección de escritos del P. Peter-Hans Kolvenbach 1991-2007, Madrid, pp. 294-310.
} 
ción de los bienes y servicios que tiene encomendados la práctica profesional que se preparan para ejercer en el futuro los actuales alumnos, se hace posible la integración de los diferentes saberes, métodos y prácticas profesionales al servicio de la vida humana de todos. La perspectiva ética (junto a otras, como la epistemológica) ofrece un horizonte integrador de los saberes que apunta a lo que estos saberes pueden y deben contribuir a mejorar las condiciones de vida de los seres humanos. Para contribuir a este cometido, la Ética necesita, utiliza y pone a disposición de cualquiera un lenguaje integrador en el que se pueda hablar de todo, dándole a cada asunto, a cada saber y a cada método su peso específico, contrapesándolo con todos los demás. Este lenguaje permite llevar a cabo la mediación entre unas disciplinas y otras, entre unos departamentos y otros, entre la universidad y la sociedad.

\section{La gestión universitaria de la pluralidad}

La políica universitaria debería ser un laboratorio de la política fuera de la universidad. La universidad actual en general y nuestros centros universitarios en particular no están ofreciendo un buen ejemplo de gestión de la pluralidad de perspectivas, disciplinas, campos y métodos. Sin embargo eso es muy importante para que la universidad sea verdadera universidad y no mera "multiversidad" ("un conjunto de departamentos unidos solamente por un sistema de calefacción" que dijo alguien). Es también decisivo para que la vida pública sepa gestionar la pluralidad de temas, intereses, grupos y perspectivas con sentido de justicia, sabiendo dar a cada asunto su peso y su derecho.

No es suficiente que haya verdadera racionalidad científica en las afirmaciones que se enseñan, se investigan o se publican; hace falta además que eso que se dice vaya acompañado de racionalidad, justicia y buen sentido en lo que se hace. La racionalidad en lo que se dice no exime de ser igualmente racionales en dar cuenta de lo que hacemos cuando actuamos dentro de la universidad. Ninguna decisión sobre por qué se priorizan los proyectos de investigación de un área de conocimiento sobre los de otra puede ser razonada en términos de ninguna de las dos áreas de conocimiento que están en disputa. Esta falta de racionalidad práctica en el debatir, cuestionar y justificar lo que se hace o deja de hacer en la universidad no tiene efectos positivos sobre la sociedad ni es precisamente ejemplar. Como dice Adela Cortina "la sociedad tiene problemas; la universidad departamentos". El feudalismo políitico y el feudalismo universitario se refuerzan mutuamente. 
La vida pública necesita, y la vida universitaria además de necesitar debería estar en condiciones de aportar una racionalidad práctica capaz de gestionar la pluralidad en permanente diálogo con las disciplinas, engarzando sus aportaciones en un sistema jerarquizado de fines al servicio de una vida humana vivida por todos en condiciones de dignidad, libertad, igualdad y prosperidad. Cada profesor universitario, cada docente y cada investigador, cada estudiante y cada miembro del equipo gestor y del personal de administración y servicios tendría que orientar sus actuaciones por una racionalidad capaz de integrar no sólo unas y otras disciplinas, sino todo lo que hace o deja de hacer, contribuye o deja de contribuir al buen hacer universitario.

Stephen Toulmin en un reciente libro 4 invita a revisar el proceso por el que la racionalidad formal de las disciplinas académicas se ha ido alejando más y más de la experiencia y de la práctica. La creciente profesionalización de la vida académica ha llevado a una creciente especialización teórica y a la consolidación de disciplinas independientes, cada vez más aisladas de toda otra disciplina con la que no comparta supuestos, planteamientos y métodos; simultáneamente se han ido también aislando de todo contexto práctico. Eso conlleva que "en las actividades profesionales de disciplinas rígidamente estructuradas, se valora más la conformidad que la originalidad; o, más bien, la originalidad se tolera solo en la medida en que refuerza los valores esenciales de un departamento... el énfasis disciplinar en las tecnicidades de las ciencias humanas impone a los recién llegados una serie de anteojeras profesionales que dirigen su atención a ciertas consideraciones restringidamente definidas, impidiéndoles a menudo considerar su trabajo desde una amplia perspectiva humana."

Toulmin concluye el capítulo dedicado a la proliferación y aislamiento de las disciplinas señalando que el problema no es tanto intelectual cuanto sociológico: "Si al final del siglo XX las actividades profesionales han desarrollado un carácter extremadamente disciplinar, lo cual ha distorsionado sus logros, debemos tratar de comprender el origen de estos problemas. No es el enfoque intelectual de la disciplina lo que produce ese efecto; sino más bien el tipo de organización social en el que se lleva a cabo la tarea disciplinar. En una palabra, éste, en el fondo, no es un fenómeno intelectual, sino sociológico." 6 "El excesivo hincapié en la pericia

\footnotetext{
${ }^{4}$ St. Toulmin (2001), Regreso a la razón, Barcelona, Península.

${ }^{5}$ Ibid., 207.

${ }^{6}$ Ibid., 227.
} 
disciplinar es, en parte, producto de la burocratización del conocimiento en las instituciones académicas." ${ }^{17}$

El funcionamiento institucional de la universidades en general, las decisiones administrativas o de política universitaria, los criterios por los que se hace esto y no lo otro, o por los que hay recursos para estos proyectos y no para los otros, a falta de un discurso compartido en términos de una racionalidad común con la que debatir los temas, no constituyen un buen ejemplo de racionalidad y justicia, ni para la sociedad ni para los jóvenes que se están preparando para trabajar en ella. La universidad no es hoy precisamente un modelo de racionalidad y justicia para la sociedad. Frente al feudalismo de los departamentos, frente a los compromisos fácticos que nadie se atreve a cuestionar, frente a decisiones que a falta de respaldo racional tienen que ser consideradas como arbitrarias, frente a un cierto pragmatismo del sentido común, sería bueno apostar por una comunidad universitaria en la que, poco a poco, se van compartiendo costumbres y razones, se va generando una cultura institucional en la que, por ósmosis y por explicitación racional, se va reconstituyendo la racionalidad práctica con la que es posible tratar los temas de justicia. Esa puede ser la mejor contribución de la institución universitaria a la construcción de una sociedad más justa.

La gestión burocrática de una realidad tan compleja como la sociedad y la universidad actual es hasta cierto punto inevitable, preferible en cualquier caso a la ausencia total de procedimientos burocráticos para resolver de manera homogéneay previsible los casos recurrentes, sea quien sea el que los plantee. Pero la burocracia, aunque venga etiquetada como calidad, no es la solución, sino que agudiza los problemas de aislamiento de las disciplinas y de falta de criterios válidos para los diferentes contextos, especialmente aquellos que no están todavía estereotipados, o que no han encontrado la forma adecuada de tramitarse de forma tipificada.

A todo lo dicho cabe añadir que en la universidad, en eventos puntuales y en la comunicación dispersa y descentralizada, debe haber debate crítico y constructivo sobre temas relevantes de la vida pública en el que se articule un discurso no puramente partidista ni ideologizado. Eso no sólo es posible, sino también factible y de hecho se viene haciendo. Al abordar esos temas candentes hay que tratar de evitar tanto la politización de la vida universitaria, no digamos de la investigación, la docencia, la gestión académica, el acceso a puestos, etc. como el desinterés por los temas de la vida pública... Ningún votante, pero menos aún si es un votante

7 Ibid., 76. 
universitario, debería meter la cabeza en la urna junto con la papeleta. Basta que meta la papeleta y siga utilizando la cabeza para pensar libremente.

\section{Conclusión}

Todas las universidades están contribuyendo, mejor o peor, a la vida pública. Lo importante es que quienes investigamos, enseñamos y trabajamos en ella lo hagamos con conciencia y responsabilidad social, pensando más en el bien público que en los intereses privados o corporativos. La misma vida universitaria, mejorando su forma de gestionar la pluralidad de disciplinas y departamentos con lenguaje y criterios éticos, podría suponer un ejemplo a seguir por una vida pública igualmente falta de formas racionales de gestionar la pluralidad. Una universidad estimulante, abierta a los temas de la vida pública suele ser el mejor caldo de cultivo de las actitudes, convicciones y usos compartidos por aquellos miembros de la nueva generación que terminarán ejerciendo responsabilidades en la vida pública. Va siendo hora de que los profesionales de conservar, acrecentar, enseñar y difundir el conocimiento científico en sus diferentes ramas nos hagamos responsables no sólo de lo que decimos o escribimos sobre nuestra propia parcela de saber, sino también de todo cuanto hacemos en la universidad, dentro y fuera de las aulas y los lugares de investigación. 